\title{
Lipoleiomyoma in a postmenopausal woman: an incidental finding
}

\author{
Sunita Samal $^{1 *}$, Sunil Kumar Samal ${ }^{1}$, Jasmina Begum ${ }^{1}$, Anandraj Vaithy ${ }^{2}$
}

\author{
${ }^{1}$ Department of Obstetrics \& Gynaecology, MGMC \& RI, Puducherry, India \\ ${ }^{2}$ Department of Pathology, MGMC \& RI, Puducherry, India
}

Received: 12 February 2015

Revised: 14 February 2015

Accepted: 01 March 2015

\section{*Correspondence:}

Dr. Sunita Samal,

E-mail: sunisamal@ rediffmail.com

Copyright: $\odot$ the author(s), publisher and licensee Medip Academy. This is an open-access article distributed under the terms of the Creative Commons Attribution Non-Commercial License, which permits unrestricted non-commercial use, distribution, and reproduction in any medium, provided the original work is properly cited.

\begin{abstract}
Lipoleiomyomas are rare variants of uterine leiomyoma, in spite of relatively common occurrence of leiomyomas of uterus. Their reported incidence varies from 0.03 to $0.2 \%$. These tumors generally occur in asymptomatic obese perimenopausal or menopausal women. The presence of fatty tissue in the myometrium is interpreted as lipomatous degeneration, smooth muscle metaplasia or as a benign tumour called as lipoleiomyoma. Imaging can play an important role in determining the intrauterine location and fatty nature of lipoleiomyomas but most of these are detected incidentally in histopathological findings postoperatively. We report a case of lipoleiomyoma in fundus of uterus in 61 years old postmenopausal female, who presented with on and off abdominal pain.
\end{abstract}

Keywords: Lipoleiomyoma, Menopause, Smooth muscle, Uterus

\section{INTRODUCTION}

Primary fatty tumours of the uterus are very uncommon and almost invariably benign. ${ }^{1}$ These tumors most probably represent tumour metaplasia within a leiomyoma. There is no definite accepted nomenclature for such tumours and it is suggested that they be designated "uterine fatty tumours" and subdivided into "lipoma" and "mixed lipoma/leiomyoma" (synonym lipoleiomyoma). ${ }^{2}$ Their reported incidence varies from 0.03 to $0.2 \%$. $^{3}$ The usual site of occurrence is within the abdominal cavity and retroperitoneum, although it may also be found in the subcutis and muscular fascia. ${ }^{4}$ Lipoleiomyoma is comprised of smooth muscle cells along with diffuse and scattered lobules of adipose tissue showing whorling at places. These tumours are seen in uterus as intramural growths but rarely may be seen arising in cervix and in broad ligament. ${ }^{5}$ It generally occurs in asymptomatic obese perimenopausal or menopausal women. We report a case of uterine lipoleiomyoma because of its rarity.

\section{CASE REPORT}

A 61 year old, multiparous postmenopausal woman presented with intermittent lower abdominal pain of 10 days duration. She attained menopause at 50 years of age. She was a known case of hypertension, diabetes mellitus and hypothyroid on treatment for last 8 years. Pelvic examination showed 14 weeks size mass which was non tender, firm and mobile. Ultrasonography revealed a uterine mass close to fundus measuring $9 \times 8 \times 8 \mathrm{~cm}$ suggestive of fibroid but possibility of ovarian teratoma was not ruled out. Endometrial thickness was $7 \mathrm{~mm}$ and both the ovaries were sonologically normal. All the standard serological and hematological parameters were within normal range. As ovarian teratoma was one of the differential diagnosis, tumor markers were tested which were within the normal limit. After control of hypertension and diabetic status, she underwent total abdominal hysterectomy with bilateral salpingooophorectomy because of the large subserous fibroid. On gross examination uterine fundus showed a solid mass of $9 \times 8 \mathrm{~cm}$ which was yellow in colour on cut section (Figure 
1). Bilateral ovaries and fallopian tubes were grossly normal. Her post-operative periods were uneventful. Histopathology showed mature adipocytes admixed with smooth muscle bundles (H\&E 10x), suggesting lipoleiomyoma (Figure 2).

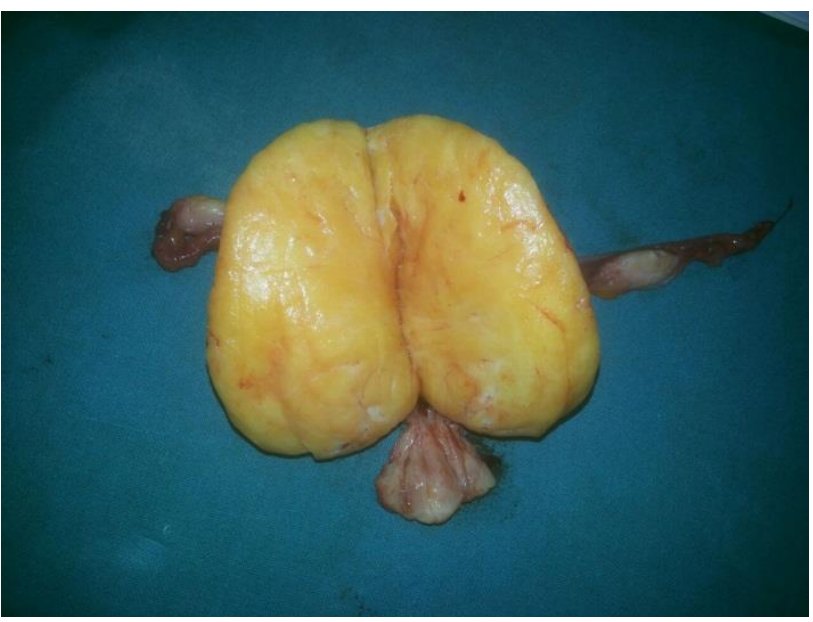

Figure 1: Gross specimen showing yellow coloured fundal fibroid and atrophic uterus on cut section.

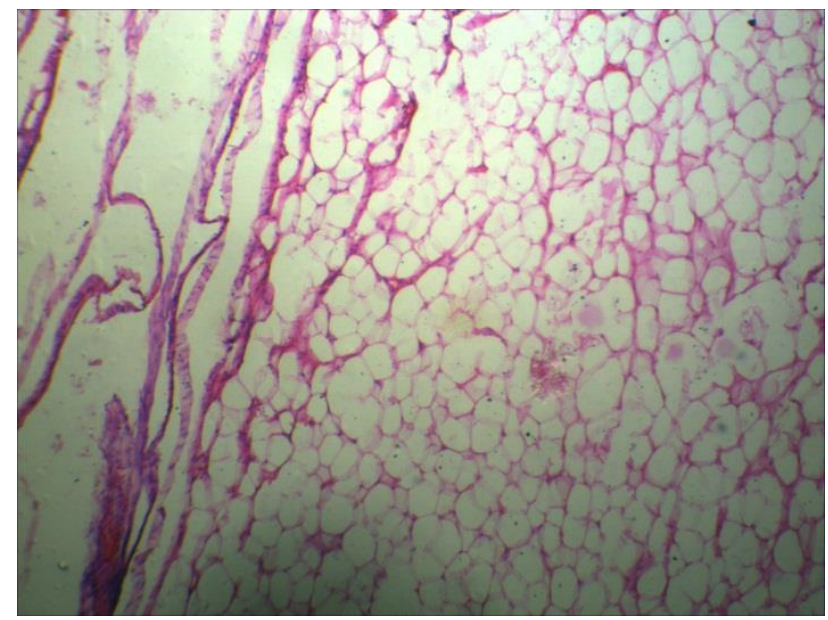

Figure 2: Histopathology showing mature adipocytes admixed with smooth muscle bundles.

\section{DISCUSSION}

Lipoleiomyoma is one of the rarer and less well known uterine masses. Like the leiomyoma of the uterus, it is also a benign, well defined mass but has a very high content of fatty or adipose tissue. These tumors showed characteristic histological findings, being composed of adipose cells, hyperplastic smooth muscle and fibrous tissue. It is believed that lipoleiomyoma of the uterus is the end result of metamorphosis of uterine smooth muscle cells within a fibroid or leiomyoma rather than the fatty degeneration. Lipoleiomyomas have also been reported in cervix, broad ligament, retroperitoneum and ovary. ${ }^{5}$ It occurs most frequently in postmenopausal women in the age group of 50-70 years as in our patient of 61 years of age. Mostly patients are asymptomatic but some experience symptoms that mimic those of uterine leiomyomas of comparable size, such as pelvic discomfort, heaviness, and vaginal bleeding. This patient presented with intermittent lower abdominal pain as it was a sessile and subserous in location. Radio imaging techniques like MRI and CT can play an important role in determining the intrauterine location and fatty nature of lipoleiomyomas but most of these are incidental findings postoperatively on histopathology. The differential diagnosis of the lipomatous mass in the pelvis includes benign cystic teratoma, malignant degeneration of cystic teratoma, non-teratomatous lipomatous ovarian tumor, benign pelvic lipomas, liposarcomas and lipoblastic lymphadenopathy. Association of lipomatous uterine tumors and endometrial carcinomas with lipoleiomyosarcoma arising in uterine lipoleiomyomas has also been reported. ${ }^{6}$ We also had a doubt of being ovarian teratoma which was ruled out by doing the tumor markers. The pathogenesis remains obscure. A number of various lipid metabolic disorders or other associated conditions, which are associated with estrogen deficiency as occurs in peri or postmenopausal period, possibly promote abnormal intracellular storage of lipids. ${ }^{7}$ Generally, small asymptomatic lipoleiomyomas do not require surgical management like that of fibroid. Surgery is useful and indicated in larger masses as in the present case and also in the presence of menstrual complaints. So, it is important to differentiate these tumors from ovarian teratoma, which requires surgical excision. Lipoleiomyomas are benign tumors which do not affect mortality.

\section{CONCLUSION}

It is the final pathological examination that confirms the diagnosis of lipoleiomyoma, though imaging plays an important role in preoperative diagnosis and localization. Lipoleiomyoma of uterine corpus are extraordinarily rare entities with clinical manifestation similar to leiomyomas, having demonstrable histology and excellent prognosis.

Funding: No funding sources

Conflict of interest: None declared

Ethical approval: Not required

\section{REFERENCES}

1. Kitajima K, Kaji Y, Imanaka K, Sugihara R, Sugimura K. MRI findings of uterine lipoleiomyoma correlated with pathological findings. AJR Am J Roentgenol. 2007;189:100-4.

2. Pounder DJ. Fatty tumours of the uterus. J Clin Pathol. 1982;35:1380-3.

3. Brandfass RT, Everts-Suarez EA. Lipomatous tumours of the uterus: a review of the world' literature with report of a case of true lipoma. Am J Obstet Gynecol. 1955;70:359-67. 
4. Oh MH, Cho IC, Kang YL, Kim CY, Kim DS, Cho $\mathrm{HD}$, et al. A case of Retroperitoneal lipoleiomyoma. J Korean Med Sci. 2001;16:250-2.

5. Rollasson TP, Wilkinson N. Non neoplastic conditions of myometrium and pure mesenchymal tumours of the uterus. In: Fox H, Wells M, eds. Haines and Taylor Obstetrical and Gynaecological Pathology. 5th ed. Edinburgh: Churchill Livingstone; 2003: 531 .
6. Lin M, Hanai J. Atypical lipoleiomyoma of the uterus. Acta Pathol Jpn. 1991;41:164-9.

7. Lin KC, Sheu BC, Huang SC. Lipoleiomyoma of the uterus. Int J Gynaecol Obstet. 1999;67:47-9.

DOI: $10.5455 / 2320-1770 . i j r \operatorname{cog} 20150449$

Cite this article as: Samal S, Samal SK, Begum J, Vaithy A. Lipoleiomyoma in a postmenopausal woman: an incidental finding. Int J Reprod Contracept Obstet Gynecol 2015;4:508-10. 